\title{
Realidad, sueño y utopía en La isla desierta. Un acercamiento al mundo teatral de Roberto Arlt
}

\author{
José Manuel Camacho Delgado \\ Departamento de Filologías Integradas, \\ Universidad de Sevilla
}

En la obra literaria del escritor argentino Roberto Arlt, la imaginación no conduce a los personajes a la liberación, sino a la derrota definitiva. Su teatro está lleno de criaturas miserables que tratan de sobreponerse inútilmente a los continuos encontronazos con la vida cotidiana. Sus obras contemplan numerosos desdoblamientos imaginativos que permiten al autor introducir diferentes niveles en la ficción y plantear el teatro dentro del teatro. En La isla desierta, una de sus piezas más breves y representadas, los personajes de una triste oficina portuaria experimentan un cambio radical en sus vidas cuando dejan de trabajar en un sótano y son trasladados a la décima planta de un inmueble. Allí, a través de un inmenso ventanal, son reclamados por un sinfín de tentaciones que se encuentran más allá del mundo gris de la oficina. Los empleados descubren los beneficios de la luz natural, la llegada de los buques, el bullicio de la calle, los reclamos de la libertad, elementos que acaban desestabilizando la rutina administrativa. No obstante, es el relato de uno de los personajes, el mulato Cipriano, cuya memoria es esencialmente literaria, el que arrastra al resto de los oficinistas a la ensoñación y a la consiguiente derrota.

En el mundo literario de Roberto Arlt la ensoñación no sirve para redimir al hombre, sino para condenarlo. Los continuos desdoblamientos imaginativos que contempla su obra sirven para sumergir a sus personajes en una realidad de catástrofe donde no hay válvulas de escape, ni puntos de fuga por los que aspirar a una situación mejor que no sea el pequeño y gran desastre de la vida cotidiana. En este sentido la dramaturgia de Roberto Arlt insiste en los temas ya desarrollados y consagrados en sus cuentos y novelas, creando una galería de perdedores que tratan de sobrevivir ante las continuas hostilidades de una realidad implacable con los más débiles. ${ }^{1}$ En su universo literario la imaginación no es libre ni gratuita. Tampoco tiene un sentido democratizador. Las criaturas miserables están condenadas a tener sueños miserables por lo que toda forma de ensoñación se acaba convir-

1 Para una síntesis de los temas y motivos más frecuentes en la literatura de Roberto Arlt véanse los trabajos de Aden W. Hayes: Roberto Arlt: la estrategia de su ficción. Londres, Thamesis, 1981, y Rita Gnutzmann: Roberto Arlt o el arte del calidoscopio. Bilbao, Servicio Editorial Universidad del País Vasco, 1984. 
tiendo en un espejo cóncavo que devuelve aún más deformada la imagen grotesca de la realidad. ${ }^{2}$

La isla desierta (1937) es todavía hoy la obra más representada de Roberto Arlt. ${ }^{3}$ En esta circunstancia intervienen numerosos factores, como es la brevedad del texto, en un solo acto, cuya lectura individual es equiparable a la de un relato corto; la accesibilidad de los elementos técnicos que hacen posible su representación y la propia naturaleza de la obra, que la convierte en una síntesis perfecta del teatro arltiano. Una obra en donde se aúnan perfectamente realidad y fantasía, cotidianidad y ensoñación, deseo y frustración. Al igual que ocurre con el conjunto de su dramaturgia, el desarrollo argumental se mueve siempre en un doble plano: el de la realidad miserable de los personajes y el de los sueños que estos son capaces de construir y que no son más que la prolongación de sus frustraciones. Sirva como ejemplo paradigmático el ofrecido en su obra Trescientos millones (1932) en donde la protagonista, una mucama a la que le ha correspondido una herencia de 300 millones con cincuenta y tres centavos, es incapaz de imaginarse una vida feliz con tanto dinero. A diferencia de la Fábula de la lechera de La Fontaine, en la que está inspirada parcialmente la obra, la sirvienta mutila cualquier conato imaginativo, impidiendo la construcción de un mundo feliz y placentero en el que ella sea la verdadera protagonista. Por el contrario, la ficción que construye alrededor de la herencia resulta truculenta y sórdida, y en ella cada motivo para el disfrute se convierte en causa de dolor y desesperanza. ${ }^{4}$

\section{La realidad de la oficina}

Siguiendo con los desdoblamientos imaginativos que permite la dramaturgia de Arlt, La isla desierta ${ }^{5}$ presenta diferentes niveles de lectura que van desde la realidad a la ensoñación de los personajes. La acción de la

2 David P. Russi: “Metatheatre: Roberto Arlt's Vehicle toward the Public's Awareness of an Art Form", Latin American Theatre Review, Kansas, Fall 1990, 24/1, págs. 65-75.

3 Mirta Arlt, hija del escritor, y Omar Borré consideran que el antecedente de esta pieza, calificada por el escritor como burlería, es un aguafuerte publicado en 1928 y que lleva por título Divagaciones acerca del empleado. En Para leer a Roberto Arlt, Buenos Aires, Torres Agüero Editor, 1984, págs. 94 y 96.

4 Para una panorámica general de su teatro, véase el libro de Raúl H. Castagnino: El teatro de Roberto Arlt. Buenos Aires, 1970.

5 La isla desierta en Obra Completa, Buenos Aires, Ediciones Carlos Lohlé, 1981, tomo 2, págs. 545-556. En adelante las citas aparecen en el propio texto. 
obra transcurre en una oficina de aduanas localizada en la décima planta de un edificio funcional que está próximo al puerto de la ciudad (suponemos que Buenos Aires). El espacio escénico aparece caracterizado en la acotación como una "oficina rectangular blanquísima, con ventanal a todo lo ancho del salón, enmarcando el cielo infinito caldeado en azul" (pág. 547). En su interior encontramos a los empleados, "desdichados" de la burocracia administrativa, quienes pasan buena parte de sus vidas encorvados sobre montañas de papeles y albaranes en un trabajo inabarcable. El mundo gris y cuadriculado de la oficina contrasta con lo que sucede más allá de los ventanales: la llegada periódica de barcos de todos los tonelajes, cuya inminente presencia viene anunciada por el pitido de las sirenas.

El contraste entre el mundo interior y exterior viene expresado por las acotaciones. Estos segmentos dramáticos, más allá de cualquier información técnica, propia del texto espectacular, ${ }^{6}$ contribuyen a crear un espacio psicológico en el lector:

"Frente a las mesas escritorios, dispuestos en hilera, como reclutas, trabajan, inclinados sobre las máquinas de escribir, los empleados. En el centro y en el fondo del salón, la mesa del JEFE, emboscado tras unas gafas negras y con el pelo cortado como la pelambre de un cepillo. Son las dos de la tarde, y una extrema luminosidad pesa sobre estos desdichados simultáneamente encorvados y recortados en el espacio por la desolada simetría de este salón de un décimo piso" (pág. 547).

(...)

"Nuevamente hay otro minuto de silencio. Durante este intervalo pasan chimeneas de buques y se oyen las pitadas de un remolcador y el bronco pito de un buque. Automáticamente todos los EMPLEADOS enderezan las espaldas y se quedan mirando la ventana" (pág. 547).

A través del enorme ventanal de la oficina los empleados reciben la sensación gratificante de la luz del sol, convertida en un símbolo positivo frente a la oscuridad de la vida cotidiana. Pero no es sólo la luz natural un elemento distorsionador en el mundo de la oficina: también lo es el sonido de los buques que anuncian su llegada a puerto, procedentes de tierras lejanas que son concebidas por los oficinistas como geografías imposibles e inalcanzables. Los empleados trabajan hora tras hora soportando la tentación que supone el llamamiento de los buques. Sus pitidos recuerdan al canto de las sirenas y como los personajes de la epopeya clásica, los oficinistas tendrán que resistir a los reclamos de la libertad. Todos esos mundos

6 Véase la obra de Fernando de Toro: Semiótica del teatro. Del texto a la puesta en escena. Buenos Aires, 1987. 
posibles que están más allá del gran ventanal de la oficina ejercen sobre los empleados una fuerza irresistible, un magnetismo que los arranca de la vulgaridad de sus vidas y hacen de la ensoñación un bastión frente a la mediocridad y la rutina.

A pesar de la riqueza de matices de las acotaciones, los personajes no están caracterizados de forma individual, sino colectiva, a través de la categoría laboral. Salvo el caso del mulato Cipriano, los oficinistas, hombres y mujeres, no tienen rostro, ni rasgos físicos, ni siquiera una manera particular de vestir. Su caracterización viene dada por la profesión que desempeñan: son empleados de aduanas con unos sueldos tan bajos como la propia autoestima. El atuendo con que se presenta ante el espectador (y lector) debe ser gris y pobre, acorde con las expectativas de sus vidas. Son además personajes arquetípicos, cuyo carácter general viene dado por la ausencia deliberada de nombres propios. Así, encontramos a El Jefe, los empleados $1 .^{\mathrm{o}}$ y $2 .^{\mathrm{o}}$, las empleadas $1 .^{\mathrm{a}}, 2 .^{\mathrm{a}}$ y $3 .^{\mathrm{a}}$ y el Director. Los únicos personajes que tienen nombre y algún rasgo singular son Manuel y María, oficinistas de toda la vida que van a cometer el error de soñar con una isla desierta, dando así nombre a la obra. Son ellos quienes más se equivocan en el cumplimiento del trabajo como consecuencia de los reclamos que están más allá del ventanal:

MANUEL.-No es posible trabajar aquí.

EL JEFE.- ¿No es posible trabajar aquí? ¿Y por qué no es posible trabajar aquí? (Con lentitud) ¿Hay pulgas en las sillas? ¿Cucarachas en la tinta?

MANUEL (poniéndose de pie y gritando).— ¿Cómo no equivocarse! ¿Es posible no equivocarse aquí? Contésteme. ¿Es posible trabajar sin equivocarse aquí?

EL JEFE.-No me falte, Manuel. Su antigüedad en la casa no lo autoriza a tanto. ¿Por qué se arrebata?

MANUEL.-Yo no me arrebato, señor. (Señalando la ventana). Los culpables de que nos equivoquemos son esos malditos buques.

EL JEFE (extrañado).—¿Los buques? (Pausa) ¿Qué tienen los buques?

MANUEL.-Sí, los buques. Los buques que entran y salen, chillándonos en las orejas, metiéndosenos por los ojos, pasándonos las chimeneas por las narices. ( $S e$ deja caer en la silla) No puedo más.

TENEDOR DE LIBROS.—Don Manuel tiene razón. Cuando trabajábamos en el subsuelo no nos equivocábamos nunca.

MARÍA.-Cierto; nunca nos sucedió esto.

EMPLEADA 1. a- - Hace siete años.

EMPLEADO 1. - ¿YYa han pasado siete años?

EMPLEADO 2. - Claro que han pasado.

TENEDOR DE LIBROS.-Yo creo, jefe, que estos buques, yendo y viniendo, son perjudiciales para la contabilidad (pág. 548). 
A la oposición interior-exterior de la oficina viene a sumarse otra dicotomía importante: la eficiencia del pasado frente a la inoperancia del presente. Las tentaciones que habitan afuera del edificio son malas para el buen funcionamiento de la oficina. La luz del sol, el aire fresco, el sonido de los buques son elementos nocivos que distraen la atención y dislocan la eficacia administrativa. Frente al desorden con que se inicia la obra, el pasado representa el orden y la disciplina, lejos de los reclamos de cualquier forma de fantasía. En el subterráneo del edificio no hay silbidos de barcos, ni aire puro, ni luz natural, sino silencio, aire viciado y luz artificial; por ello, nada puede distraer la atención de los oficinistas. Para el Empleado 1. "Uno estaba allí tan tranquilo como en el fondo de una tum$b a$ " (pág. 550) y Manuel afirma que allí se sentían "como una lombriz solitaria en un intestino de cemento" (pág. 554). Ascender al décimo piso del bloque de oficinas no es sólo una forma de subir físicamente, sino sobre todo espiritualmente. La visión que tienen del puerto, de las calles y de los buques los acerca a una realidad que ha estado fuertemente reprimida y que acaba presentándose como un deseo, como una ensoñación.

\section{El mulato Cipriano}

El personaje que se encarga de conectar el mundo interior con el exterior, y el pasado con el presente es el mulato Cipriano. Aunque conocemos su nombre, éste siempre viene señalado antes de sus intervenciones como "mulato", lo que le confiere un rasgo distintivo con respecto a los otros personajes de la oficina. Su color representa el mestizaje, la fusión, la síntesis y el sincretismo. Pero también representa un elemento perturbador en el mundo de los empleados "blancos" por cuanto su concepto de la vida y de la libertad está lejos de los usos europeístas para entroncar con el modus vivendi de las culturas negroafricanas. Arlt lo presenta como un "MULATO, simple y complicado, exquisito y brutal, y su voz por momentos persuasiva" (pág. 550). Estamos ante un personaje que representa una totalidad y un sentido global de las cosas. En realidad, más que una criatura singular con rasgos propios, su construcción obedece a tradiciones literarias diversas y su memoria no es la de un hombre normal, sino la de un arquetipo: Cipriano representa al viajero utópico de la literatura y la historiografía colonial.

Vestido con "uniforme color de canela" (pág. 550), Cipriano es el ordenanza que lleva y trae los recados de la oficina. Es el único que puede 
entrar y salir del edificio en horas de trabajo (y de sol) por lo que su presencia sirve para conectar las dos realidades. Sin embargo, Cipriano no es un personaje pasivo y sumiso como podría suponérsele por su condición de ordenanza, sino que es un hombre rebelde y su carácter instigador va a poner en funcionamiento la pequeña tragedia vivida por los otros personajes. ${ }^{7}$ El mulato se presenta ante sus compañeros como un verdadero experto en la ciencia náutica: conoce el tonelaje y calado de los buques, el recorrido que realizan, el astillero en el que fueron construidos, el día que los botaron y todo lo referente al arte de marear. Según informa, ha sido "grumete, lavaplatos, marinero, cocinero de veleros, maquinista de bergantines, timonel de sampanes, contramaestre de paquebotes..." (pág. 551). A tenor de sus conocimientos merecería ser ingeniero naval o capitán de fragata, a pesar de la incredulidad, e incluso la burla, con que los otros personajes oyen el relato de su experiencia marinera:

MULATO (sin mirar al que lo interrumpe).-Desde los siete años que doy vueltas por el mundo, y juro que jamás en la vida me he visto entre chusma tan insignificante como la que tengo que tratar a veces...

MARÍA ( $a$ EMPLEADA $10^{\mathrm{a}}$ ).- - A buen entendedor...

MULATO.-Conozco el mar de las Indias. El Caribe, el Báltico... hasta el océano Ártico conozco. Las focas, recostadas en los hielos, lo miran a uno como mujeres aburridas, sin moverse...

EMPLEADO 2. - ¡Che, debe hacer un fresco bárbaro por ahí!

EMPLEADA 2. - - Cuente, Cipriano, cuente. No haga caso.

MULATO (sin volverse).- -Aviada estaría la luna si tuviera que hacer caso de los perros que ladran. En un sampán me he recorrido el Ganges. Y había que ver los cocodrilos que nos seguían...(pág. 551).

La memoria de Cipriano es arquetípica y esencialmente literaria. Conecta con la de los grandes viajeros del periodo colonial, entre los que cabría destacar a Antonio Pigafetta, y entronca de forma definitiva con toda la literatura utópica que se desarrolla al calor de los grandes descubrimientos geográficos realizados a lo largo de los siglos XVI y XVII. Cipriano habla de lugares paradisíacos, a mitad de camino entre la Arcadia clásica y la Utopía (1516) de Tomás Moro:

7 Raúl H. Castagnino ha escrito al respecto: "La burocracia se desconcierta: el horizonte acuático, las chimeneas humeantes de las naves, los mástiles erguidos invitan a la ensoñación. Y a los empleados sólo les basta el estímulo de un mulato tentador para imaginar una isla paradisíaca donde vivir una nueva edad de oro en vez de seguir llenando providencias en manoseados expedientes de trámite. El absurdo mágico y magia de lo absurdo entran en juego". Véase El teatro de Roberto Arlt, pág. 88 . 
MULATO.-Allá no hay jueces, ni cobradores de impuestos, ni divorcios, ni guardianes de plaza. Cada hombre toma a la mujer que le gusta y cada mujer al hombre que le agrada. Todos viven desnudos entre las flores, con collares de rosas colgantes del cuello y los tobillos adornados de flores. Y se alimentan de ensaladas de magnolias y sopas de violetas.

TODOS.-Eh, eh...

EMPLEADA 2. ${ }^{\text {a }-~ ¡ E h ! ~ ¡ C i p r i a n o, ~ q u e ~ n o ~ n a c i m o s ~ a y e r ! ~}$

MULATO.-Juro que se alimentan de ensalada de magnolias.

TODOS.-No.

MULATO.-Sí.

EMPLEADO 2. - - Mucho... mucho...

MULATO.-Digo que sí. Y además los árboles están siempre cargados de toda clase de fruta.

MANUEL.-No será como la que uno compra aquí, en la feria.

MULATO.-Allá no. Cuelgan libremente de las ramas y quien quiere, come, y quien no quiere, no come... y por la noche, entre los grandes árboles, se encienden fogatas y ocurre lo que es natural que ocurra entre hombres y mujeres

EMPLEADA $1 .{ }^{\text {a }-i Q u e ́ ~ p a i ́ s e s, ~ q u e ́ ~ p a i ́ s e s ! ~}$

MULATO.-Y digo que es muy saludable vivir así libremente. Al otro día la gente trabaja con más ánimo en los arrozales y si uno tiene sed (toma el vaso de agua y bebe), parte un coco y bebe su deliciosa agua fresca” (pág. 553).

El testimonio literario de Cipriano evoca el paraíso perdido, como ocurre en el mundo rural de la Arcadia o en la Edad de Oro y refiere el anhelo de un futuro mejor, como representa todo testimonio utópico. Aunque cribado y cuestionado siempre por la burla de los otros oficinistas, Arlt pone en manos de su personaje una puntada más en ese inmenso tapiz que representan las sociedades ideales, como La ciudad del Sol (1602) de Campanella, la Nueva Atlántida (1627) de Francis Bacon, Cristianápolis (1619) de Johann Valentin Andreä o la Océana (1656) de James Harrington. ${ }^{8}$ En ese mundo ideal e insular, el hombre vive en perfecta armonía con el espacio natural que le proporciona todo lo que necesita para su felicidad. El tópico del homo faber, capaz de sobrevivir en completa autarquía y libertad, contrasta con el empleado que ha perdido en la maraña administrativa su propia identidad. Es la utopía mestiza, o la nueva raza cósmica, dominadora del Universópolis, como la concibió el pensador mexicano José Vasconcelos (1925) en su famoso ensayo de interpretación de la sociedad americana.

8 Véanse las obras de Fernando Ainsa: La reconstrucción de la Utopía. México, Correo de la Unesco, 1999 y Louis Rougier: Del paraíso a la utopía. México, F.C.E., 1984. 


\section{Cipriano y los tatuajes}

El tatuaje posee en todas las épocas una riquísima simbología. A lo largo de la historia, la escritura de la piel ha tenido un profundo carácter religioso, como se desprende del propio Génesis bíblico, ${ }^{9}$ pero también ha sido utilizado como un signo de distinción, sobre todo por parte de los pueblos paganos y en la cultura clásica. El origen del tatuaje se pierde en el tiempo y es anterior a cualquier testimonio escrito. No obstante, la palabra "tatuaje" procede, según Corominas, de la forma polinesia "tatau" y fue introducida en Europa por los exploradores Cook y Bouganville en sus respectivos viajes de 1769. El viajero francés reproduce la voz "tatau" y Cook la llama "tattowing". Este último introdujo el término en la Relación de su primer viaje alrededor del mundo, tras su estancia en la isla de Tahití:

"Es en ellos corriente pintarse el cuerpo, casi de la misma manera que en otras partes del mundo, practicando lo que ellos llaman tattowing. Se escarifican la piel, punto menos que hasta hacer saltar la sangre, con un pequeño instrumento que tiene la forma de una azada; la parte que corresponde a la pala es de hueso o de concha muy fina, y su anchura, de una pulgada o de pulgada y media; el borde está guarnecido de agudos dientes, en número de tres a veinte, según su tamaño; cuando va a utilizarse lo humedecen en un líquido que preparan mezclando una especie de hollín que se forma con el humo que se desprende al quemar una nuez oleaginosa de que se sirven para alumbrarse, y agua; los dientes así preparados se colocan sobre la piel, e imprimen pequeñas y ligeras sacudidas al mango del instrumento con un palo a propósito; perforan la piel de esta manera e introducen en ella al mismo tiempo, en los puntos heridos, la nueva composición, que deja un tinte indeleble". ${ }^{10}$

Todo parece indicar que el tatuaje, en cualquiera de sus manifestaciones rituales, puede ser rastreado a lo largo de todas las épocas, desde

9 Sus orígenes míticos se remontan al Génesis bíblico, a la señal puesta por Dios a Caín para preservar su estirpe a lo largo de todos los tiempos. "Entonces dijo Caín a Yahveh: 'Mi culpa es demasiado grande para soportarla. Es decir que hoy me echas de este suelo y he de esconderme de tu presencia, convertido en vagabundo errante por la tierra, y cualquiera que me encuentre me matará'. Respondióle Yahveh: 'Al contrario, quienquiera que matare a Caín, lo pagará siete veces'. Y Yahveh puso una señal a Caín para que nadie que le encontrase le atacara" (Génesis, 4).

10 La cursiva es de Cook. Primer viaje alrededor del mundo, Madrid, Espasa Calpe, 1944, 3 vols., págs. 199-200. Sobre el sentido que puedan tener estas marcas escribe en la página 200 lo siguiente y se encuentra en: "La operación es penosa y los heridos tardan algunos días en curarse; se sufre por los de ambos sexos entre doce y catorce años y se efectúa en diversas partes del cuerpo y según figuras variadas, obedeciendo a la fantasía del padre o tal vez del rango familiar. Las mujeres están marcadas en forma de $\mathbf{Z}$ por las juntas de los dedos de los pies y de las manos y frecuentemente por la parte superior de los pies; la marca de los hombres tiene la misma figura, y tanto estos como las mujeres presentan cuadros, círculos y medias lunas y figuras mal dibujadas de hombres, aves o perros, y otras varias representaciones, en piernas y brazos, algunas de las cuales se nos dijo tenían significación, aunque nunca pudimos saber cuáles fueran". 
Alaska a la Tierra de Fuego y desde España a la lejana Australia. Sabemos que en tumbas egipcias pertenecientes al año 3500 a. C. se han encontrado estatuillas con marcas y rasgos que pueden ser considerados como tatuajes. En el mundo clásico Herodoto nos informa de que las mujeres troyanas eran tatuadas como signo de distinción y nobleza. Algo parecido nos cuenta Plinio de los hombres de algunas tribus de Samaria y Tracia. ${ }^{11}$ Galos, normandos, bretones y godos parecen compartir esta misma inquietud por el tatuaje. Hasta aquí algunas pinceladas sobre la Europa pagana, sin embargo, algo muy diferente ocurrió en el mundo cristiano.

El origen mítico que se le atribuye al tatuaje en el Antiguo Testamento no puede ser más maldito. Quizás sea esta la principal razón por la que las autoridades eclesiásticas ratificaron su condena por considerarlo una práctica pagana y contraria al mandamiento de Dios. Recuérdese la prohibición recogida en el Levítico 19,28 ("No haréis incisiones en vuestra carne por los muertos; ni os haréis tatuaje. Yo Yahveh"). Sin embargo, esto no fue impedimento para que las prácticas de este signo se mantuvieran en algunos sectores de la población, acostumbrados a la vida errante y al contacto con otras civilizaciones. Me refiero a los cruzados medievales, a los viajeros, a los exploradores y, fundamentalmente, a los navegantes. Cruces, gallos, Vírgenes y el tradicional San Jorge luchando contra el dragón pasaron a convertirse en la prueba irrefutable de que alguien había estado en el lugar mencionado.

El momento de mayor esplendor del tatuaje se produce a finales del siglo XVI con los asentamientos de colonos europeos en tierras orientales, sobre todo en contacto con la cultura nipona. Sin embargo, desde comienzos de siglo resultan muy interesantes los testimonios coloniales ofrecidos por Antonio Pigafetta $(1519-1522)^{12}$ y Francis Fletcher (1577-1580), ${ }^{13}$ en

11 Herodoto nos informa de la extraña costumbre de llevar tatuajes porque ya en esta época tales prácticas estaban asociadas a las culturas marginales. Estos "stigmata” eran característicos de los esclavos, quienes habían sido marcados con un hierro al rojo vivo. El fragmento pertenece a su Historia, libro V,6, Madrid, Gredos, 1981, pág. 21, traducción de Carlos Schrader: "En cambio, vigilan celosamente a sus esposas (a estas últimas se las compran a sus padres a un elevado precio). Llevar tatuajes está considerado como un signo de nobleza, y de baja ralea no llevarlos" (la cursiva es mía).

Otras referencias sobre el tema las encontramos en Aristófanes, Aves, 760; Esquines, De falsa legatione, 79; Luciano, Timón 17; Diógenes Laercio, V,46; Cicerón, De officis II 7,5; Dión Crisóstomo, XIV, 19. Otros autores recogen observaciones parecidas para diferentes pueblos: Estrabón VII 5,4, para los ilirios; Anábasis V 4,32, para los mosinecos; y Pomponio Mela II, 10, para los agatirsos.

12 Antonio Pigafetta: Primer viaje alrededor del mundo (edición de Leoncio Cabrero). Madrid, 1985, pág. 69.

13 El capellán Francis Fletcher fue compañero de viaje de Francis Drake en su vuelta alrededor del mundo. Su testimonio ha sido recogido por Hans Damm en el volumen titulado Francis Drake. Piraterías en América. Madrid, Bruno del Amo Editor, 1929, págs 70 y ss. 
sus viajes de circunnavegación terráquea. El tatuaje ha estado desde siempre íntimamente ligado al mundo marinero. Piratas, comerciantes, traficantes de negros o simples grumetes han adornado su piel con las ya consabidas anclas, barcos o serpientes marinas. La simbología de estos motivos es grande y responde casi siempre a un deseo innato de comunicación, sobre todo cuando el hombre está en contacto permanente con la muerte y lejos de su realidad familiar. El hombre de mar escribe en su piel todo aquello que quiere recordar y hace de su cuerpo una segunda memoria, un salvoconducto para el más allá, una especie de mensaje para Caronte. El tatuaje es en definitiva la prueba de que el hombre recurre a sí mismo y a su menuda geografía para afianzarse y preservarse en un mundo que todo lo olvida. Los motivos tatuados dependen de factores tan diversos como la posición que se ocupe en una embarcación, el lugar por donde se transite o el número de millas marinas recorridas. Alberto García Alix ha escrito al respecto:

"Habiendo recorrido 5.000 millas marinas se tatuaban un pájaro azul en el pecho; si habían recorrido 10.000 millas, añadían al anterior un segundo pájaro al otro lado del pecho; cuando realizaban más cruceros, se tatuaban una cuerda para tender con ropa interior y medias de chicas. Si cruzaban el ecuador, ponían un Neptuno en la pierna, y para seguridad se tatuaban un cerdo en un pie y un gallo en el otro, tatuajes ambos que les protegían de morir ahogados. Un dragón demostraba que habían cruzado un meridiano, y todo marinero que había estado en Honolulú tatuaba una chica hawaiana en su brazo para hacerla bailar". ${ }^{14}$

Toda una vida dedicada a la navegación habrá hecho de muchos hombres auténticos murales vivientes, como ocurre con el propio José Arcadio Buendía en Cien años de soledad ${ }^{15}$ o Queequeg en la novela Moby Dick, de Herman Melville. Por eso, el mulato Cipriano utiliza los tatuajes como prueba irrefutable sobre la veracidad de su relato:

MULATO (violento).- - A mí nadie me trata de mentiroso, ¿sabe? (Arrebatado, se quita la chaquetilla, y luego la camisa, que muestra una camiseta roja, que también se saca).

EMPLEADA 1. a - ¿Qué hace, Cipriano?

EMPLEADA 2. ${ }^{a}$ —Está loco?

EMPLEADA $3 .^{\text {a }}$-Cuidado, que puede venir el jefe.

MULATO.--Vean, estos tatuajes. Digan si éstos son tatuajes hechos entre la línea del Tigre o Constitución. Vean...

EMPLEADA 2. ${ }^{\text {— }}$ ¡Una mujer en cueros!

14 Alberto García Alix: "El tatuaje”, Suplemento dominical de 'El Pais', 5 de enero de 1992.

15 José Manuel Camacho Delgado: "José Arcadio y el mundo de los piratas", en Huellas, Revista de la Universidad del Norte, Barranquilla, n. ${ }^{\circ}$ 43, abril de 1995, págs. 20-27. 
MULATO.-Este tatuaje me lo hicieron en Madagascar, con una espina de tiburón. EMPLEADO 2. —iQué mala espina!

MULATO.- - Vean esta rosa que tengo sobre el ombligo. Observen qué delicadeza de pétalos. Un trabajo de indígenas australianos.

EMPLEADO 2. - ¿ ¿No será una calcomanía?

EMPLEADA 2. - - ¿Qué va a ser calcomanía! Éste es un tatuaje de veras.

MULATO.-Le aseguro, señorita, que si me viera sin pantalones se asombraría...

TODOS.- ¡Oh... ah!...

MULATO (enfático).- - Sin pantalones soy extraordinario.

EMPLEADA $1 .{ }^{\text {a }}$-No se los pensará quitar, supongo.

MULATO._¿Por qué no?

EMPLEADA $3 .^{\text {a }}$ - No, no se los quite.

MULATO.- - No voy a quedar desnudo por eso. Y verán qué tatuajes tengo labrados en las piernas.

EMPLEADA $1 .{ }^{\mathrm{a}}$ - Es que si entra alguien...

EMPLEADA $3 .^{\text {a }}$-Cerrando la puerta (Va a la puerta).

MULATO (quitándose los pantalones y quedando con un calzoncillo corto y rojo con lunares blancos).-Miren estos dibujos. Son del más puro estilo malasio. ¿Qué les parece esta guarda de monos pelando bananas? (Murmullos de "Oh... ah..."). Lo menos que merezco es ser capitán de una isla. (Toma un pliego de papel madera y rasgándolo en tiras se lo coloca alrededor de la cintura). Así van vestidos los salvajes de las islas.

EMPLEADA 1. ${ }^{\text {a }}$ - ¿A las mujeres también les hacen tatuajes?...

MULATO.-Claro. ¡Y qué tatuajes! Como para resucitar a un muerto.

EMPLEADA 2. ${ }^{\mathrm{a}-}-i$ Y es doloroso tatuarse?

MULATO.- No mucho... Lo primero que hace el brujo tatuador es ponerlo a uno bajo un árbol...

EMPLEADA 2. ${ }^{\text {a }-U y, ~ q u e ́ ~ m i e d o . ~}$

MULATO.-Ningún miedo. El brujo acaricia la piel hasta dormirla. Y uno acaba por no sentir nada.

EMPLEADO $1 .^{\circ}-$ Claro...

MULATO.-Siempre bajo los árboles hay hombres y mujeres haciéndose tatuar. Y uno termina por no saber si es un hombre, un tigre, una nube o un dragón” (pág. 552).

Como se desprende de este fragmento, Cipriano hace de sus tatuajes un certificado para demostrar su pasado viajero por los mares remotos del planeta. Los datos que apunta tienen un evidente valor antropológico y su correspondencia con las prácticas reales del tatuaje son bastante aproximadas, lo que demuestra el conocimiento que Arlt tenía de esta particular escritura de la piel, propia también del mundo marginal (delincuencia, drogas, alcohol) que él conoció de primera mano y del que hizo un material narrativo excepcional para sus propias ficciones.

Pero además de certificar la autenticidad de relato, Cipriano introduce un elemento nuevo en el mundo tedioso de los oficinistas: la sensuali- 
dad y el erotismo. Despojado de los ropajes que le caracterizan como un ordenanza de la oficina, el mulato se transforma en una criatura libre que hace del movimiento un reclamo para la libertad: "El mulato toma la tapa de la máquina de escribir y comienza a batir el tam tam ancestral, al mismo tiempo que oscila simiesco sobre sí mismo (pág. 555). La siguiente acotación insiste en el carácter transgresor del personaje que gesticula "como un demonio" y "toca el tambor y habla el condenado negro". Dentro del mundo tedioso de los oficinistas, no cabe duda que Cipriano es un demonio tentador que trata de subvertir el orden establecido. Y lo consigue parcialmente cuando los empleados giran alrededor de la oficina y bailan imitando el movimiento del mulato:

"Histéricamente todos los hombres se van quitando los sacos, los chalecos, las corbatas; las muchachas se recogen las faldas y arrojan los zapatos. El MULATO bate frenéticamente la tapa de la máquina de escribir. Y cantan un ritmo de rumba” (pág. 556).

La danza tiene un sentido ritual y transgresor. Propicia la desnudez simbólica y la liberación de las tensiones internas, reforzada por el particular striptease que ellos protagonizan de manera espontánea y natural. Siguiendo el llamamiento del tambor, los personajes han alcanzado por una vez en sus vidas la libertad, y con ella la ensoñación. Pero como ocurre siempre en su teatro - y en sus novelas- la ensoñación sólo es el preludio de una caída mayor en el carácter sórdido de la realidad. Siguiendo el ideario del fracaso trazado en obras como Trescientos millones (1932), Prueba de amor (1932) o Saverio el cruel (1936), Roberto Arlt no deja lugar para que los personajes escapen de la realidad miserable que les rodea. La fantasía, la imaginación o el sueño se convierten en espejos deformantes que devuelven desde la representación o la lectura, la imagen de unas vidas mutiladas, incapaces de soñar con total libertad. En La isla desierta el final de la obra no se corresponde con la muerte de su protagonista (o protagonistas) como ocurre en las piezas anteriores, sino con el despido de todos los empleados. La entrada del jefe y del director en la oficina mientras los personajes bailan semidesnudos alrededor del mulato se va a resolver con la expulsión de todos los partícipes de esta bacanal administrativa. Para preservar la eficiencia burocrática y evitar futuros cantos de sirena procedentes del puerto, el director ordenará poner vidrios opacos en la ventana, arrancando de cuajo todo vínculo con el exterior. Es así como la décima planta del edificio se convierte de nuevo en un espacio cerrado y claustrofóbico, un locus horrendus en el que el hombre es arrasado junto con sus tentaciones de utopía. 